\title{
Inhibition of de novo DNA Methyltransferase 3B is a Potential Therapy for Hepatocellular Carcinoma
}

\author{
Hong Fan ${ }^{\mathrm{a}, \mathrm{b}}$, Jian Chenga ${ }^{\mathrm{a}}$, Zhu Jiang Zhao ${ }^{\mathrm{a}}$
}

\begin{abstract}
Background: Aberrant epigenetic patterns, including inactivation of tumor suppressor genes due to DNA methylation, have been described in many human cancers. Epigenetic therapeutic is a new and rapidly developing area of tumor treatment because DNA methyltransferase (DNMT) inhibitors can reverse its changes. We attempted to identify potential approach for epigenetic therapy of hepatocellular carcinoma
\end{abstract}

Methods: We knocked down the expression of DNMT 1 or DNMT 3B by siRNA, and inhibited DNA methyltranferases by 5-Aza-2'deoxycytidine. We used high-density oligonucleotide gene expression microarrays to examine the induced genes in human hepatocellular carcinoma cell line SMMC-7721 after suppressing DNA methyltranferases. The 5' ends of up-regulated genes were analyzed by BLAST database to determine whether they have promoter $\mathrm{CpG}$ islands, and then the identical induced genes were compared among different inhibition of DNA methyltranferases.

Results: Our results show that 9 genes were found to be over expressed by more than two-fold induced by DNMT1 siRNA and 5-Aza-CdR, and 30 genes were found to be over expressed by more than two-fold induced by DNMT3B siRNA and 5-Aza-CdR in SMMC-7721. Among them, 76.6\% up-regulated genes conjectural contained 5' CpG islands. The DNMT3B siRNA could induce more genes identical to demethylation agent in SMMC-7721.

Conclusions: DNMT3B might be a new potential target for therapy of hepatocellular carcinoma.

Manuscript received October 24 ; accepted November 6, 2008

aKey Laboratory of Developmental Genes and Human Disease, Ministry of Education, Southeast University; Department of Genetics and Development, Southeast University Medical School. 87 Dingjiaqiao, Nanjing 210009, Jiangsu Province, China

${ }^{\mathrm{b} C}$ Corresponding Author: Department of Genetics \& Developmental Biology, Key Laboratory of Developmental Genes and Human Disease, Ministry of Education, Southeast University, 87 Dingjiaqiao Road, Nanjing, P. R. China, 210009. Email: fanh@seu.edu.cn

doi:10.4021/gr2008.10.1240
Key words: Epigenetic, therapy, DNMTs, Hepatocellular Carcinoma, 5-Aza-CdR, siRNA, CpG islands, methylation

\section{Introduction}

Cancer is an epigenetic disease due to aberrant epigenetic patterns in the development of human cell, especially in abnormal DNA methylation. Transcriptional silencing of tumor-suppressor genes by $\mathrm{CpG}$ methylation may contribute to tumorigenesis. Moreover, the potential way is to drug-induced reactivation of methylation silenced tumor suppressor genes. 5-Aza-2'-deoxycytidine (5-Aza-CdR) inhibits DNA methylation and often is used in vitro to induce the re-expression of genes putatively silenced by promoter methylation (1).

5-Aza-CdR is substituted for cytosine during replication and recognized by DNA methyltransferases (DNMTs)(2). This treatment ultimately depletes cellular stores of DNMTs and results in widespread genomic hypomethylation(3). In addition to reactivation of methylation-silenced tumor-suppressor genes, 5-aza-Cyd and 5-aza-dCyd are highly toxic in cultured cells $(4,5)$ and animals $(6,7)$.

DNA methylation of $\mathrm{CpG}$ dinucleotides is known to be mediated by at least three DNMTs, including DNMT3A, DNMT3B, and DNMT1. DNMT3A and DNMT3B are de novo methyltransferases that initiate the methylation process, whereas DNMT1, the maintenance methyltransferase, directs methylation of the newly synthesized strand complimentary to the hemimethylated DNA(8). Studies suggested that over-expression of DNMT1 and /or DNMT3B involved in tumorigenesis and development of most cancers(9-12), including hepatocellular carcinoma(13). The DNMT1 siRNA treatment led to a partial removal of DNA methylation from inactive promoter $\mathrm{CpG}$ islands, and restored the expression of tumor suppressor genes(14). Gene targeting experiments have shown that DNMT3B plays an important role in the hypermethylation of $\mathrm{CpG}$ islands in human cancers(15). Rhee(16) demonstrated that somatic cell knockouts of both DNMT3B and DNMT1 genes led to demethylation and reexpression of tumor suppressor genes in a colon cancer cell 
line. We used a combination of genetic (siRNA) and pharmacological (5-aza-2'-deoxycytidine) inhibitors of DNMTs to study the contribution of the DNMT isotypes to cancer-cell methylation. In the current study, we investigated the effects of 5-aza-2'-deoxycytidine alone and suppression of DNMT1 or DNMT3B on human hepatoma cell lines. We try to explore the possibility of treatment strategy to hepatocellular carcinoma (HCC) by modifying the aberrant methylation.

\section{Materials and methods}

\section{Cell Culture and 5-Aza-CdR Treatment}

The human hapetocellular carcinoma cell line SMMC7721 was obtained from the Cell Bank (Shanghai, China). Cell lines were maintained in RPIM1640 medium supplemented with $12 \%$ heat-inactivate NBS, 100 units $/ \mathrm{ml}$ of penicillin, and 100 units $/ \mathrm{ml}$ of streptomycin. Cells were cultured at $75 \mathrm{ml}$ flask and treated in the next day with $100 \mathrm{uM} \mathrm{5-Aza-}$ CdR (Sigma Chemical Co., St. Louis, MO) up to 4 days. The cultured medium was changed 3 days after treatment, and total RNA was extracted at day 3 from exponentially growing cultures.

Preparation of siRNA of DNMT, a vector-based siRNA construct and transfection of DMMT RNAi construct to hepatocellular carcinoma cell line SMMC-7721

SiRNAs targeting DNMT1 or DNMT3B were designed and prepared as previous described $(17,18)$. The siRNA sequences against DNMT1 were designed as sense and antisense oligonucleotides corresponding to nucleotide position 2,620-2,638 of human DNMT1 (GenBank accession No. NM001379.1). The sequence of DNMT3B siRNA corresponds to nucleotide position 470-488 of DNMT3B (GenBank accession no. AF331857), there was no homology with other human genes was found by scanning the GenBank of NCBI using these siRNA.

The human hepatocellular carcinoma cell line SMMC7721 (No. TCHu13 Cell Bank Shanghai, China) was maintained by serial passage in RPMI 1640 (Life Technologies, Inc., Rockville, MD) containing 10\% heat-inactivated new born bovine serum, $100 \mathrm{U} / \mathrm{ml}$ penicillin and $100 \mathrm{mg} /$ $\mathrm{ml}$ streptomycin, and incubated at $37^{\circ} \mathrm{C}, 5 \% \mathrm{CO} 2,95 \%$ air using the standard tissue culture incubators. One day before transfection, cells were seeded in order that they were $30-50 \%$ confluent the next day. Cells were transfected with 1.5ug of DNMT1 or DNMT3B siRNA (pMT1 or pMT3B) construct using transfectamine transfection reagent (Invitrogen) reduced serum medium at $37^{\circ} \mathrm{C}$ in a $5 \% \mathrm{CO} 2$ atmosphere for $5 \mathrm{~h}$. The medium was removed and replaced with fresh RPMI 1640 supplemented with 20\% new born bovine serum. Control cells were treated with transfectamine alone or with pSUPER-GFP plasmid. Cells were grown and selectively cultured in $0.4 \mathrm{mg} / \mathrm{ml}$ Genetincin (life technologies) for two months after the initial transfection. The cells stably harboring targeting vector were monitored with GFP expres-

Table 1. Genes altered more than 2-fold after 5-Aza-CdR and pMT1 treatment in the hepatocellular carcinoma SMMC-7721 cell line

\begin{tabular}{lllll}
\hline & $\begin{array}{l}\text { GenBank_ } \\
\text { ID }\end{array}$ & $\begin{array}{l}\text { Gene_ } \\
\text { Symbol }\end{array}$ & $\begin{array}{l}\text { 5'CpG island } \\
\text { (CGI) }\end{array}$ & Function \\
\hline Regulation of transcription & NM_182917 & EIF4G1 & CGI & regulation of translational initiation \\
Signal transduction & NM_002733 & PRKAG1 & CGI & regulates adipose differentiation \\
& NM_004583 & RAB5C & CGI & signal transduction, regulation \\
Others & NM_016219 & MAN1B1 & CGI & hydrolase activity \\
& NM_017883 & WDR13 & CGI & mRNA processing \\
& NM_000526 & KRT14 & None & epidermis development \\
& NM_004860 & FXR2 & CGI & insulin receptor binding \\
& NM_005993 & TBCD & CGI & integrin-mediated signaling pathway \\
& NM_000034 & ALDOA & CGI & RNA binding
\end{tabular}

aBased on a PubMed search; CGI, 5' CpG island; None, no known 5' CpG island. 
sion. SMMC-7721 cells were transfected with pMT1 named as 7721-MT1 cell lines, with pMT3B named as 7721-MT3B cell lines.

\section{RNA extraction and synthesis of cDNA first strand}

Total RNA was extracted using TRIZOL (Gibco BRL, Life Technologies Inc.,) according to the manufacturer's protocol. RNA was resuspended in DEPC treated water and quality verified by agarose gel electrophoresis stained by EB. Total RNA was reverse transcribed using $2 \mu \mathrm{g}$ of RNA and oligo-dT (18) (Life Technologies, Inc.) in a 13.5-ul reaction. The oligo-dT-RNA mixture was placed at $70^{\circ} \mathrm{C}$ for $2 \mathrm{~min}$ and then rapidly cooled to $0^{\circ} \mathrm{C}$. Then, the Superscript II reverse transcriptase and its MIX (Life Technologies, Inc.) was supplied into the oligo-dT-RNA mixture followed by $42^{\circ} \mathrm{C}$ for $60 \mathrm{~min}$, and $90^{\circ} \mathrm{C}$ for $5 \mathrm{~min}$ and then rapidly cooled to $0^{\circ} \mathrm{C}$.

\section{cDNA microarrary}

The 14K cDNA microarrary used in this study were obtained through the Shanghai BioChip Co., Ltd. The 14K slides contained human genes together with 10 positive and 6 negative controls. The spotting patterns and the complete annotated list of cDNAs are available at the following web site: http://www.shbiochip.com. The 5'ends of the genes upregulated in this manner were analyzed in the BLAST database to determine whether they have promoter $\mathrm{CpG}$ islands.

\section{Results}

\section{5-Aza-CdR induced genes expression in global changes}

We first assessed the global changes in gene expression induced by 5-Aza-CdR in the liver tumor cell line exposed to $100 \mathrm{uM} 5$-Aza-CdR for 4 days. We analyzed those genes that were up- or down-regulated by more than 2.5 -fold 4 days after drug treatment and categorized the genes as to whether or not they are known to be in some pathways. The 5' ends of the genes up-regulated in this manner were analyzed in the BLAST database to determine whether they might have promoter $\mathrm{CpG}$ islands. The data showed that only $70 \%$ upregulated genes in the hepatocellular carcinoma cell line definitely contained 5' $\mathrm{CpG}$ islands.

SiRNA of DNMT1 or DNMT3B constructs induced genes expression in global changes not only in those containing CpG island in the promoter regions

We next assessed the global changes in gene expression induced by siRNA of DNMT1 constructs or siRNA of DNMT3B constructs in hepetocellular carcinoma cell lines SMMC-7721. There is some information indicating that genes of non- $\mathrm{CpG}$ island promoter up-regulates expression induced by knockdown DNMT1 or DNMT3B, therefore, the mechanism by which the knockdown of DNMT1 or DNMT3B activated genes without $\mathrm{CpG}$ islands remains unclear.

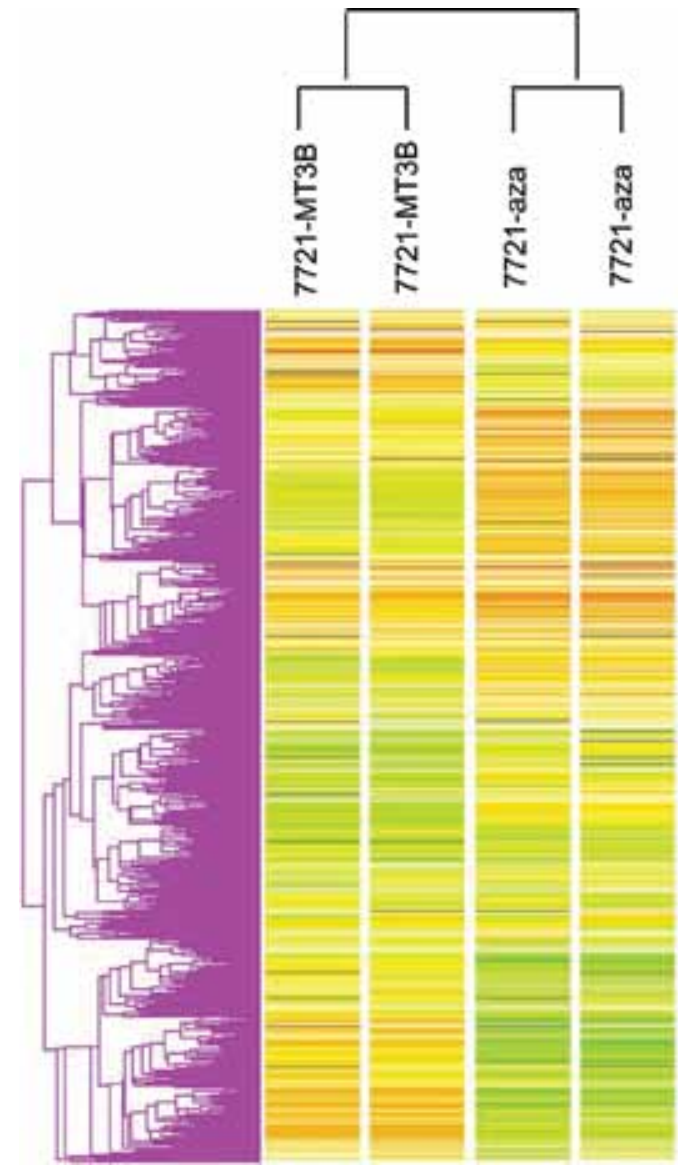

Figure 1. Hierarchical clustering based on gene expression data from SMMC-7721 DNMT3B unsuppressed and suppressed cells and SMMC-7721 5-Aza-CdR untreated and treated cells.

SiRNA of DNMT3B induces more genes identical to induced by 5-Aza-CdR than siRNA of DNMT1 in hepatocellular carcinoma cells

We compared those genes that both were up-regulated by DNMT1 siRNA and 5-Aza-CdR treatment, and also compared up-regulated genes both were induced by DNMT3B siRNA and 5-Aza-CdR treatment. A total of 9 genes were found to be over expressed by more than two-fold induced by DNMT1 siRNA and 5-Aza-CdR in SMMC-7721 (Table 1). The 5' ends of the genes up-regulated in this manner were analyzed in the BLAST database to determine whether they have promoter $\mathrm{CpG}$ islands. The data showed that almost all of up-regulated genes contained 5' $\mathrm{CpG}$ islands except KRT14. We next focused our attention on those genes that induced by DNMT3B siRNA with demethylation drug. A total of 30 genes were found to be over expressed by more than two-fold induced by DNMT3B siRNA and 5-Aza-CdR in SMMC-7721. The 5' ends of the genes up-regulated in this 
Table 2. Genes altered by more than 2.5-fold after pMT3B and 5-Aza-CdR treatment in the hepatocellular carcinoma cell line SMMC-7721

\begin{tabular}{|c|c|c|c|}
\hline GenBank_ID & Symbol & $\begin{array}{l}5 \text { CpG island } \\
(C G I)^{a}\end{array}$ & Function \\
\hline \multicolumn{4}{|l|}{ Cell differentiation } \\
\hline NM_006096 & NDRG1 & CGI & cell differentiation \\
\hline \multicolumn{4}{|l|}{ Cell proliferation } \\
\hline NM_005557 & KRT16 & NO & cell proliferation \\
\hline NM_013402 & FADS1 & CGI & regulation of cell differentiation \\
\hline \multicolumn{4}{|l|}{ Regulation of transcription } \\
\hline NM_003926 & MBD3 & CGI & regulation of transcription \\
\hline NM_005253 & FOSL2 & CGI & regulation of transcription \\
\hline \multicolumn{4}{|l|}{ Signal transduction } \\
\hline NM_138769 & ARHT2 & CGI & signal transduction \\
\hline NM_004218 & RAB11B & CGI & signal transduction \\
\hline NM_145173 & DIRAS1 & CGI & signal transduction \\
\hline \multicolumn{4}{|l|}{ Others } \\
\hline NM_017510 & HSGP25L2G & CGI & intracellular protein transport \\
\hline NM_006700 & FLN29 & CGI & nucleic acid binding \\
\hline NM_001956 & EDN2 & NO & protein kinase $\mathrm{C}$ activation \\
\hline NM_057089 & AP1S1 & CGI & intracellular protein transport \\
\hline NM_020196 & $\mathrm{XAB} 2$ & CGI & DNA repair \\
\hline NM_006412 & AGPAT2 & CGI & metabolism \\
\hline NM_001074 & UGT2B7 & NO & metabolism \\
\hline NM_006247 & PPP5C & CGI & regulation of I-kappaB kinase/NF-kappaB cascade \\
\hline NM_002273 & KRT8 & NO & cytoskeleton organization and biogenesis \\
\hline NM_006445 & PRPF8 & CGI & nuclear mRNA splicing, via spliceosome \\
\hline NM_002233 & KCNA4 & CGI & potassium ion transport \\
\hline NM_004204 & PIGQ & CGI & carbohydrate metabolism \\
\hline NM_004818 & DDX23 & CGI & protein kinase $\mathrm{C}$ activation \\
\hline NM_017458 & MVP & NO & response to drug \\
\hline NM_032038 & SPINL & CGI & tetracycline transport \\
\hline NM_020230 & PPAN & CGI & RNA splicing \\
\hline NM_001897 & CSPG4 & CGI & cell motility \\
\hline NM_021979 & HSPA2 & NO & male meiosis \\
\hline NM_018110 & DOK4 & CGI & insulin receptor binding \\
\hline NM_144568 & C14orf9 & CGI & hydrolase activity \\
\hline
\end{tabular}

'Based on a PubMed search; CGI, 5' CpG island; None, no known 5' CpG island. 
manner were analyzed in the BLAST database to determine whether they have promoter $\mathrm{CpG}$ islands. The data showed that $76.6 \%$ up-regulated genes conjectural contained 5' $\mathrm{CpG}$ islands (Table 2). Hierarchical clustering of gene expression in untreated and treated cells is shown in Fig. 1. As expected, some similarities in gene expression were seen between untreated cell by DNMT3B RNAi and 5-Aza-CdR.

\section{Discussion}

Epigenetic mechanisms including DNA methylation and histone modifications are one of the most important means of gene expression regulation. More and more evidences indicated that epigenetic modifications have a crucial role in cancer development. Epigenetic therapy is also a potential therapy because epigenetic defects are thought to be more easily reversible with pharmacological intervention(19, 20). Aberrant DNA hypermethylation, a prevalent alteration in most tumor playing a key role in human carcinogenesis, involved in global hypomethylation(21-23), specific gene hypermethylation(24-26) and loss of imprinting (LOI) $(27,28)$. DNMTs are responsible for setting up and maintenance of DNA methylation in biological process and thought to be involved in tumorigenesis. Therefore DNMTs theoretically serve as a reasonable target for anti-tumor therapy. In preclinical work, DNMT inhibitors have reversed the growth of cancer cell lines and demonstrated antineoplastic effects in animal models, including prolongation of survival(29, 30). One such agent, 5-aza-2'-deoxycytidine (5-aza-CdR), is a potent inhibitor of genomic and promoter-specific DNA methylation(25). However, there also are limitations of epigenetic therapeutic agents for prevention of tumorigenesis due to lack of specificity, these result in accelerated tumor progression $(31,32)$ and drug toxicity $(33,34)$. Moreover, it is necessary to find a better way to correct epigenetic abnormity in tumor, especially in DNA methylation.

Evidences showed that DNMT1 and DNMT3B cooperatively maintain DNA methylation and gene silencing in human cancer cells $(16,35)$. DNMT3B may not only silence genes by several mechanisms including direct DNA methylation or recruitment of proteins that modify chromatin, but also play an important role in transformation $(36,37)$. DNMT3B over-expression may be involved in the suppression or lower expression of p14ARF and p16INK4a observed in esophageal squamous cell carcinoma(38). The DNMT1 or DNMT 3B can be considered as a target for epigenetic therapy in human tumor. Antisense oligonucleotides are short, defined sequences of nucleotides that are complementary to mRNAs and hybridize with them and make them inactive, thereby blocking translation. Antisense oligonucleotides that are complementary to mRNA for human DNMT1 are undergoing preclinical(39) as well as clinical(40) trials. RNA interference (RNAi) is a natural mechanism in organisms in resistance to virus invasion and inhibition of transposon mobility by double stranded RNA (dsRNA).

Latest study shows that 21-25 nt small interference RNA (siRNA) can mediate specific gene silencing in mammal cells(41). Being effective and highly specific, RNAi probably becomes a novel technique in knocking gene down and plays important roles in gene function study and gene therapy of diseases(42). In this study, we try to knock down the expression of DNMT1 or DNMT3B via siRNA to explore the mechanism of DNMTs involved in hepatoma therapy. An advantage of using high-throughput oligonucleotide microarray data from treated cell lines is to enable us to provide a conservative estimate of the number of genes directly affected by aberrant methylation in hepatocellular carcinoma cell line. There are different induced genes by suppression of DNMTs among DNMT1 siRNA, DNMT3B siRNA and demehylation drug. Compared with inhibition of DNMT1, DNMT3B siRNA induced more tumor-related genes identical to that of demehylation drug 5-aza-2'-deoxycytidine.

Approximate $33.3 \%$ (10/30) genes were reported to be involved in tumorigenesis, such as FADS1, MBD3, MVP, DIRAS1 and so on. Among them, there are $76.6 \%$ up-regulated genes conjectural contained 5' $\mathrm{CpG}$ islands. These data indicated a new strategy in therapy of hepatocellular carcinoma through suppression of DNMT3B rather than treatment with demethylation agent. Because it has not been reported that DNMT3B are highly toxic in cultured cells and animals. Recently, frequent epigenetic changes such as DNA hypo- and hypermethylation and altered methylation pattern have been observed in hepatocellular carcinoma $(43,44)$. In fact, over-expression of DNMT3b4 is involved in human hepatocarcinogenesis, even at the precancerous stages by affecting the expression of specific genes(45). An increase in the DNMT3B mRNA levels in hepatocellular carcinoma relative to their non-cancerous tissues may be a predictor of poor survival(46). Over expression of a splice variant of DNMT 3B, DNMT3b4, is associated with DNA hypomethylation on pericentromeric satellite regions during human hepatocarcinogenesis(47). One of the novel findings of our present study is that DNMT3B siRNA could induce more genes identical to demethylation agent in hepatocellular cancer. Although these results need to be extended in larger clinical studies, this may serve as a potential new approach for hepatocellular carcinoma.

\section{Acknowledgement}

This work was supported by grants of the National Natural Science Foundation of China (NO. 30470950). Thanks Dr. Peng Hou from department of Biomedical Engineering of Southeast University for supplying the $\mathrm{CpG}$ island through the BLAST. Thanks for the Shanghai gene chip company of China to supplying the analysis of gene expression. The au- 
thors declare no commercial associations or conflict of interest related to this article.

\section{References}

1. Bender CM, Zingg JM, Jones PA DNA methylation as a target for drug design. Pharm Res 1998;15:175-187.

2. Momparler RL. Molecular, cellular and animal pharmacology of 5-aza-2'-deoxycytidine. Pharmacol Ther 1985;30:287-299.

3. Karpf AR, Peterson PW, Rawlins JT, Dalley BK, Yang Q, Albertsen H, Jones DA. Inhibition of DNA methyltransferase stimulates the expression of signal transducer and activator of transcription 1, 2, and 3 genes in colon tumor cells. Proc Natl Acad Sci USA 1999;96:14007-14012.

4. Flatau E, Gonzales FA, Michalowsky LA, Jones PA. DNA methylation in 5-aza-2'-deoxycytidine-resistant variants of C3H 10T1/2 C18 cells. Mol Cell Biol 1984; 4:2098-2102.

5. Davidson S, Crowther P, Radley J, Woodcock D. Cytotoxicity of 5-aza-2'-deoxycytidine in a mammalian cell system. Eur J Cancer 1992;28:362-368.

6. Jaenisch R, Schnieke A, Harbers K. Treatment of mice with 5-azacytidine efficiently activates silent retroviral genomes in different tissues.Proc Natl Acad Sci USA 1985;82:1451-1455.

7. Richel DJ, Colly LP, Lurvink E, Willemze R. Comparison of the antileukaemic activity of 5 aza-2-deoxycytidine and arabinofuranosyl-cytosine in rats with myelocytic leukaemia. Br J Cancer 1988;58:730-733.

8. Okano M, Bell DW, Haber DA, Li E. DNA methyltransferases Dnmt3a and Dnmt3b are essential for de novo methylation and mammalian development. Cell 1999;99:247-257.

9. Robertson KD, Uzvolgyi E, Liang G, Talmadge C, Sumegi J, Gonzales FA, Jones PA. The human DNA methyltransferases (DNMTs) 1, 3a and 3b: coordinate mRNA expression in normal tissues and overexpression in tumors. Nucleic Acids Res 1999; 27:2291-2298.

10. Szyf M, Detich N. Regulation of the DNA methylation machinery and its role in cellular transformation. Prog Nucleic Acid Res Mol Biol 2001;69:47-79.

11. Kimura F, Seifert HH, Florl AR, Santourlidis S, Steinhoff C, Swiatkowski S, Mahotka C, Gerharz CD, Schulz WA. Decrease of DNA methyltransferase 1 expression relative to cell proliferation in transitional cell carcinoma. Int J Cancer 2003;104:568-78.

12. Girault I, Tozlu S, Lidereau R, Bieche I. Expression analysis of DNA methyltransferases 1, 3A, and $3 \mathrm{~B}$ in sporadic breast carcinomas. Clin Cancer Res 2003;9:4415-4422.

13. Nagai M, Nakamura A, Makino R, Mitamura K.
Expression of DNA (5-cytosin)-methyltransferases (DNMTs) in hepatocellular carcinomas. Hepatol Res 2003;26:186-191.

14. Leu YW, Rahmatpanah F, Shi H, Wei SH, Liu JC, Yan PS, Huang TH. Double RNA interference of DNMT3b and DNMT1 enhances DNA demethylation and gene reactivation. Cancer Res 2003;63:6110-6115.

15. Weisenberger DJ, Velicescu M, Cheng JC, Gonzales FA, Liang G, Jones PA. Role of the DNA methyltransferase variant DNMT3b3 in DNA methylation. Mol Cancer Res 2004;2:62-72.

16. Rhee I, Bachman KE, Park BH, Jair KW, Yen RW, Schuebel KE, Cui H, Feinberg AP, Lengauer C, Kinzler KW, Baylin SB, Vogelstein B. DNMT1 and DNMT3b cooperate to silence genes in human cancer cells. Nature 2002;416:552-556.

17. Fan H, Xu J, Wu S, Zhao Z, Zhang J, Xie W. Construction of DNMT1 siRNA stable expressing vector and evaluation of its silenced efficiency in blocking gene expression. Zhonghua Yi Xue Yi Chuan Xue Za Zhi 2005;22:142-145.

18. Xu J, Fan H, Zhao ZJ, Zhang JQ, Xie W. Identification of potential genes regulated by DNA methyltransferase $3 \mathrm{~B}$ in a hepatocellular carcinoma cell line by RNA interference and microarray analysis. Yi Chuan Xue Bao 2005;32:1115-1127.

19. Issa JP. Epigenetic variation and human disease. J Nutr 2002;132:2388S-2392S.

20. Blanchard F, Chipoy C. Histone deacetylase inhibitors: new drugs for the treatment of inflammatory diseases? Drug Discov Today 2005;10:197-204.

21. Ehrlich M, Jiang G, Fiala E, Dome JS, Yu MC, Long TI, Youn B, Sohn OS, Widschwendter M, Tomlinson GE, Chintagumpala M, Champagne M, Parham D, Liang G, Malik K, Laird PW. Hypomethylation and hypermethylation of DNA in Wilms tumors. Oncogene 2002;21:6694-6702.

22. Tsuda H, Takarabe T, Kanai Y, Fukutomi T, Hirohashi S. Correlation of DNA hypomethylation at pericentromeric heterochromatin regions of chromosomes 16 and 1 with histological features and chromosomal abnormalities of human breast carcinomas. Am J Pathol 2002;161:859866.

23. Sato N, Maitra A, Fukushima N, van Heek NT, Matsubayashi $\mathrm{H}$, Iacobuzio-Donahue CA, et al. Frequent hypomethylation of multiple genes overexpressed in pancreatic ductal adenocarcinoma. Cancer Res 2003;63:4158-66.

24. Ordway JM, Bedell JA, Citek RW, Nunberg A, Garrido A, Kendall R, Stevens JR, Cao D, Doerge RW, Korshunova Y, Holemon H, McPherson JD, Lakey N, Leon J, Martienssen RA, Jeddeloh JA. Comprehensive DNA methylation profiling in a human cancer genome identifies novel epigenetic targets. Carcinogenesis 2006;27:2409-2423. 
25. Iida S, Akiyama Y, Nakajima T, Ichikawa W, Nihei Z, Sugihara K, Yuasa Y. Alterations and hypermethylation of the p14(ARF) gene in gastric cancer. Int $\mathrm{J}$ Cancer 2000;87:654-658.

26. Mares J, Sedlacek Z, Goetz P. DNA methylation and neoplasms. Cas Lek Cesk 2000;139:291-294.

27. Nakagawa H, Chadwick RB, Peltomaki P, Plass C, Nakamura Y, de La Chapelle A. Loss of imprinting of the insulin-like growth factor II gene occurs by biallelic methylation in a core region of H19-associated CTCFbinding sites in colorectal cancer. Proc Natl Acad Sci USA 2001;98:591-596.

28. $\mathrm{Xu} \mathrm{W,} \mathrm{Fan} \mathrm{H,} \mathrm{He} \mathrm{X,} \mathrm{Zhang} \mathrm{J,} \mathrm{Xie} \mathrm{W.} \mathrm{LOI} \mathrm{of} \mathrm{IGF2} \mathrm{is}$ associated with esophageal cancer and linked to methylation status of IGF2 DMR. J Exp Clin Cancer Res 2006;25:543-547.

29. Bigey P, Knox JD, Croteau S et al. Modified oligonucleotides as bona fide antagonists of proteins interacting with DNA. Hairpin antagonists of the human DNA methyltransferase. J Biol Chem 1999; 274:4594-4606.

30. Covey JM, Zaharko DS. Comparison of the in vitro cytotoxicity (L1210) of 5-aza-2'-deoxycytidine with its therapeutic and toxic effects in mice. Eur J Cancer Clin Oncol 1985;21:109-117.

31. Hill BT, Whatley SA, Bellamy AS, Jenkins LY, Whelan RD. Cytotoxic effects and biological activity of 2-aza8-germanspiro[4,5]-decane-2-propanamine-8, 8-diethyl-N, N-dimethyl dichloride (NSC 192965; spirogermanium) in vitro. Cancer Res 1982;42:2852-2856.

32. Landolph JR, Jones PA. Mutagenicity of 5-azacytidine and related nucleosides in $\mathrm{C} 3 \mathrm{H} / 10 \mathrm{~T} 1 / 2$ clone 8 and V79 cells. Cancer Res 1982;42:817-23.

33. Momparler RL, Frith $\mathrm{CH}$. Toxicology in mice of the antileukemic agent 5-aza-2'-deoxycytidine. Drug Chem Toxicol 1981;4:373-381.

34. Vesely J, Cihak A. 5-Aza-2'-deoxycytidine: preclinical studies in mice. Neoplasma 1980;27:113-9.

35. Ghoshal K, Bai S. DNA methyltransferases as targets for cancer therapy. Drugs Today (Barc) 2007;43:395422.

36. Soejima K, Fang W, Rollins BJ. DNA methyltransferase $3 \mathrm{~b}$ contributes to oncogenic transformation induced by SV40T antigen and activated Ras. Oncogene 2003; 22:4723-4733.

37. Beaulieu N, Morin S, Chute IC, Robert MF, Nguyen H, MacLeod AR. An essential role for DNA methyltransferase DNMT3B in cancer cell survival. J Biol Chem 2002;277:28176-81.

38. Simão Tde A, Simões GL, Ribeiro FS, Cidade DA,
Andreollo NA, Lopes LR, Macedo JM, Acatauassu R, Teixeira AM, Felzenszwalb I, Pinto LF, Albano RM. Lower expression of p14ARF and p16INK4a correlates with higher DNMT3B expression in human oesophageal squamous cell carcinomas. Hum Exp Toxicol 2006;25:515-522.

39. Yan L, Nass SJ, Smith D, Nelson WG, Herman JG, Davidson NE. Specific inhibition of DNMT1 by antisense oligonucleotides induces re-expression of estrogen receptor-alpha (ER) in ER-negative human breast cancer cell lines. Cancer Biol Ther 2003;2:552-556.

40. Davis AJ, Gelmon KA, Siu LL, Moore MJ, Britten CD, Mistry N, Klamut H, D'Aloisio S, MacLean M, Wainman N, Ayers D, Firby P, Besterman JM, Reid GK, Eisenhauer EA. Phase I and pharmacologic study of the human DNA methyltransferase antisense oligodeoxynucleotide MG98 given as a 21-day continuous infusion every 4 weeks. Invest New Drugs 2003;21:85-97.

41. Fire A, Xu S, Montgomery MK, Kostas SA, Driver SE, Mello CC. Potent and specific genetic interference by double2stranded RNA in Caenorhabditis elegans. Nature 1998;391:806-811.

42. Patrick J P, Amy AC, Gregory J H. Stable suppression of gene expression by RNAi in mammalian cells. Proc Natl Acad Sci USA 2002; 99:1443-1448.

43. Lin CH, Hsieh SY, Sheen IS, Lee WC, Chen TC, Shyu WC, Liaw YF. Genome-wide hypomethylation in hepatocellular carcinogenesis. Cancer Res 2001;61:42384243.

44. Park HJ, Yu E, Shim YH. DNA methyltransferase expression and DNA hypermethylation in human hepatocellular carcinoma. Cancer Lett 2006;233:271-278.

45. Kanai Y, Saito Y, Ushijima S, Hirohashi S. Alterations in gene expression associated with the overexpression of a splice variant of DNA methyltransferase $3 \mathrm{~b}, \mathrm{DN}-$ MT3b4, during human hepatocarcinogenesis. J Cancer Res Clin Oncol 2004;130:636-644.

46. Oh BK, Kim H, Park HJ, Shim YH, Choi J, Park C, Park YN. DNA methyltransferase expression and DNA methylation in human hepatocellular carcinoma and their clinicopathological correlation. Int $\mathrm{J}$ Mol Med 2007;20:65-73.

47. Saito Y, Kanai Y, Sakamoto M, Saito H, Ishii H, Hirohashi S. Overexpression of a splice variant of DNA methyltransferase 3b, DNMT3b4, associated with DNA hypomethylation on pericentromeric satellite regions during human hepatocarcinogenesis Proc Natl Acad Sci USA 2002;99:10060-10065. 